\title{
A descriptive sensory analysis of honeybee drone brood from Denmark and Norway
}

Evans, Joshua David; Müller, A.; Jensen, Annette Bruun; Dahle, B.; Flore, Roberto; Eilenberg, Jørgen; Frøst, Michael Bom

Published in:

Journal of Insects as Food and Feed

DOI:

10.3920/JIFF2016.0014

Publication date:

2016

Document version

Publisher's PDF, also known as Version of record

Citation for published version (APA):

Evans, J. D., Müller, A., Jensen, A. B., Dahle, B., Flore, R., Eilenberg, J., \& Frøst, M. B. (2016). A descriptive sensory analysis of honeybee drone brood from Denmark and Norway. Journal of Insects as Food and Feed, 2(4), 277-283. https://doi.org/10.3920/JIFF2016.0014 


\title{
A descriptive sensory analysis of honeybee drone brood from Denmark and Norway
}

\author{
J. Evans ${ }^{1 *}$, A. Müller ${ }^{1,2}$, A.B. Jensen ${ }^{3}$, B. Dahle ${ }^{4,5}$, R. Flore ${ }^{1}$, J. Eilenberg ${ }^{3}$ and M.B. Frøst ${ }^{1}$ \\ ${ }^{1}$ Nordic Food Lab, Department of Food Science, University of Copenhagen, Rolighedsvej 30, 1958 Frederiksberg C, Copenhagen, \\ Denmark; ${ }^{2}$ Department of Social Sciences, Humboldt-Universität zu Berlin, Universitätsstraße 3B, 10117 Berlin, Germany; \\ ${ }^{3}$ Department of Plant and Environmental Sciences, University of Copenhagen, Thorvaldsensvej 40, 1871 Frederiksberg C, \\ Denmark; ${ }^{4}$ Norwegian Beekeepers Association, Dyrskuev 20, 2040 Kløfta, Norway; ${ }^{5}$ Department of Animal and Aquacultural \\ Sciences, Norwegian University of Life Sciences, P.O. Box 5003, 1432 Ås, Norway; je@nordicfoodlab.org
}

Received: 21 March 2016 / Accepted: 19 May 2016

(c) 2016 Wageningen Academic Publishers

\section{OPEN ACCESS @(1)(-) RESEARCH ARTICLE}

\begin{abstract}
Honeybee (Apis mellifera) brood is enjoyed as food in many regions of the world. The Nordic region of Europe is not currently one of them, but it could be. The drone brood in particular constitute an untapped source of delicious, nutritious and potentially sustainable food. Currently, it is removed by many beekeepers as part of a strategy to lower the population of the destructive Varroa mite (Varroa destructor) in the hive, but most often it is disposed of. A descriptive sensory analysis of drone brood was conducted, using larvae and pupae from four hives, three in Denmark and one in Norway, from locations spanning a range of urban/rural and monocultural/polycultural surroundings. Data were collected with a panel of 10 subjects using fast sensory methods, and were analysed with analysis of variance-partial least squares regression. The first dimension accounted for $40 \%$ of the variance, and correlated closely with differences in developmental stage between larvae and pupae; the second dimension accounted for $16 \%$ of the variance, and most closely grouped samples from three of the locations apart from those of the fourth. Developmental stage was thus found to be the primary determinant of sensory profile, followed by variations in locality, possibly related to local forage. Further studies should investigate the different parameters of sensory profile in more detail to develop a more complex picture of drone brood's taste and culinary potential - an important part of developing strategies to diversify our food sources and realise certain insects' ecological, culinary, and economic potential for local food systems.
\end{abstract}

Keywords: edible insects, larvae, Nordic, pupae, taste

\section{Introduction}

The brood of the honeybee (Apis mellifera) is eaten as food in multiple regions of the world (Van Huis et al., 2013), and valued as a nutritious delicacy (Rumpold and Schlüter, 2013). The precedents for its use as human food paired with its widespread range and co-evolutionary history with humans give strong support to investigating the potential of using honeybee brood, particularly that of the drones (males), as a local, nutritious, delicious ingredient in regions where it is not currently used as food, and instead where in many cases it goes to waste.

One such area - and there are many, as the honeybee is a widespread cosmopolitan species - is the Nordic region of Europe. Drone brood is already removed from beehives as part of a strategy to control the population of Varroa mites (Varroa destructor). The rationale for this practice relies on the fact that the mite preferentially reproduce on drone brood (Charriere et al., 2003), which have a longer developmental period than worker brood, with the result of Varroa's higher reproductive success in drone cells (2.2-2.6 mites per cell) than in worker cells (1.3-1.4 mites per cell; Fuchs and Langenbach, 1989; Schulz, 1984). Beekeepers around the world have developed multiple methods for addressing the so-far intractable problem of Varroa infestation (Dietemann et al., 2012; Rosenkranz et al., 2010), and trapping the mites in drone brood frames has become generally recognised as one of the more sustainable practices to combat Varroa (Calis, 2001). In Denmark, many 
beekeepers use the so-called 'safe strategy', which involves removing one-third of a comb frame of drone brood per week during the drone brood season from May to July in hope of reducing the mite population over the course of the year (Vejsnæs et al., 2005). As a result of this practice, Danish beekeepers currently remove many tonnes of drone brood comb every year (K. Foley, A. Lecocq and A.B. Jensen, unpublished data). Some beekeepers feed this removed brood to chickens or other animals, but many, especially those in urban areas, do not, and some have expressed the desire or have made attempts to find another purpose for this resource rather than having to dispose of it (Gade and Theuerkauf, 2016; M. Eismann, personal communication; O. Maxwell, personal communication).

Honeybee drone brood has some particular properties that make it attractive for culinary experimentation. It has a rich nutritional profile, averaging $20 \%$ protein and $50 \%$ fat by dry weight (Rumpold and Schlüter, 2013), and the nutritional value of worker brood does not seem to be significantly changed by Varroa infestation (Jonas-Levi et al., 2015). Furthermore, due to their widespread availability during the spring/early summer season, they presented themselves as one of the most worthwhile insect species in the Nordic region to investigate for their potential to contribute to local cuisine and local food systems. Honeybee drone brood is, unsurprisingly, not a commodity in regions where they are not typically considered food, and consequently there is no existing market for them. This state may however change once their potential and value is recognised, new infrastructure created, and once eaters develop edible relationships with them. In fact, direct local use of honeybee drone brood could come to be one concrete way of realising the promising claims of insects' sustainable potential that currently dominate the discourse (Müller et al., 2016; Van Huis et al., 2013). But in order to integrate them into cuisine and thus make them 'edible', we must first understand more about how they taste and how they respond to cooking (Halloran et al., 2015).
Recent gastronomic research has developed techniques and recipes to facilitate knowledge dissemination of drone brood as a new ingredient in the Nordic context (Barthouil, 2013; Evans, 2012; Evans et al., 2015). The present study was conducted to characterise the taste properties of drone brood, at two different developmental stages and from hives at four locations with different local forage, as part of investigating the culinary potential of local honeybee colonies. We applied a fast-sensory method because it gives an appropriate balance of precision and ease of execution for a first inquiry into the subject.

\section{Materials and methods}

\section{Samples}

The honeybees from the Norwegian colony belong to the subspecies Apis mellifera subsp. carnica, and those from the Danish colonies belong to the hybrid Apis mellifera $\times$ buckfast, bred from several subspecies of A. mellifera. Drone brood larvae and pupae were obtained from a single hive from each of four different locations (Table 1). These locations were chosen to cover a range of locations from urban (Frederiksberg and Amager in Copenhagen) to rural (Gyrstinge and Austmarka) and with local forage from more monocultural (fields of rape, Brassica napus, in Gyrstinge) to more polycultural (gardens and green spaces in Frederiksberg, Amager, and Austmarka). Rather than representing clear-cut binaries, these distinctions function as rough axes to facilitate the selection of samples across a continuum of environmental conditions.

Capped drone brood were harvested in the comb during the same week in all four hives, and frozen immediately. During transport the combs were kept frozen and either shipped (from Norway) or transported directly to Nordic Food Lab in Copenhagen via car (from Gyrstinge), bicycle (from Amager), or a short walk (from Frederiksberg). Immediately after arrival at Nordic Food Lab, the brood was frozen further with liquid nitrogen to facilitate separation and

Table 1. Samples of bee brood from four different locations in Denmark (DK) and Norway (NO), differentiated by developmental stage, degree of urban/rural surroundings, and degree of monocultural/polycultural surroundings.

$\begin{array}{lllll}\text { Sample } & \text { Location of hive } & \text { Developmental stage } & \text { Urban/rural } & \text { Mono/polycultural surroundings } \\ 1 & \text { Gyrstinge, DK } & \text { larvae } & \text { rural } & \text { monocultural } \\ 2 & \text { Gyrstinge, DK } & \text { pupae } & \text { rural } & \text { monocultural } \\ 3 & \text { Frederiksberg, Copenhagen, DK } & \text { larvae } & \text { urban } & \text { polycultural } \\ 4 & \text { Frederiksberg, Copenhagen, DK } & \text { pupae } & \text { urban } & \text { polycultural } \\ 5 & \text { Amager, Copenhagen, DK } & \text { larvae } & \text { urban } & \text { polycultural } \\ 6 & \text { Amager, Copenhagen, DK } & \text { pupae } & \text { urban } & \text { polycultural } \\ 7 & \text { Austmarka, NO } & \text { larvae } & \text { rural } & \text { polycultural } \\ 8 & \text { Austmarka, NO } & \text { pupae } & \text { rural } & \text { polycultural }\end{array}$


cleaning of the wax, separated into larvae and pupae (only white-eyed pupae were used, before their eyes turn purple as part of their next stage of development), sealed in vacuum bags and kept frozen (A.B. Jensen et al., unpublished data) until the sensory analysis.

\section{Subjects}

The panel consisted of ten panellists familiar with the fast sensory method used. Many but not all had some degree of prior experience with tasting bee brood. The panel consisted of 3 women and 7 men; their ages ranged from 24 to 44 years with a mean of 30 years.

\section{Experimental design}

The analysis was carried out in a standard sensory room during the day with both natural and overhead light. Panellists were seated at individual tables, with a large sheet of paper, sticky notes, a pen, water and neutral crackers to refresh the palate. The 8 brood samples were given randomised 3-digit numbers; six of each sample were placed in small plastic trays labelled with each corresponding number, which were then placed in randomised order on top of a frozen ice-pack to keep the delicate brood chilled. The subjects were instructed to taste the samples from left to right beginning with the top-left (to counterbalance any carry-over effect), note down up to five descriptors of the sensory properties of the sample (smell, taste, texture) on one sticky note for each sample (Frøst et al., 2014), and place the sticky note on the large sheet of paper. They were instructed to move the sticky notes around as they tasted more samples in order to arrive at a configuration that to them best represented the similarities and differences between the samples, and to mark the final positions in pen with an ' $\mathrm{x}$ '.

\section{Sensory analysis methodology}

It is common in sensory analysis to limit a test to be either descriptive or affective (Lawless and Heymann, 2010, Chapter 10). Previous studies have conducted sensory analyses of different insect species and products with different panels, and have primarily studied consumer acceptance (Lensvelt and Steenbekkers, 2014; Tan et al., 2015). Few if any have focussed on honey bee brood. We have chosen to use the descriptive method, for which experienced panellists are preferred; further studies with bee brood might assess hedonics/consumer acceptance, which tend to prefer panellists unfamiliar with the food in question.

The experimental set-up and instructions given to the participants were according to the instructions for napping (Pagès 2003; Perrin and Pagès 2009) with some exceptions, making it more similar to projective mapping (Risvik et $a l ., 1994)$. The respondents were asked to write down the descriptors as they taste each individual sample, not at the end. This gives better flow during tasting, and is suitable for use with trained and semi-trained respondents (Frøst et al., 2014).

In addition respondents were specifically instructed to focus on taste, smell and texture characteristics of the bee brood. This variant is sometimes referred to as partial mapping and was chosen because this variant was shown to produce results more similar than holistic mapping to those of conventional descriptive analysis (Dehlholm, 2012).

These methods are characterised as 'fast sensory methods' - fast and simple enough to be executed in a timely and cost-effective manner while still giving robust, detailed data. These fast sensory methods suited our purposes better than traditional sensory methods for this study, as they provided a time- and resource-efficient way to take a first exploratory step into descriptive sensory analysis of insects, in order to assess its suitability for further inquiry.

\section{Statistical analysis}

Positions of individual samples were digitised by measuring the position in $\mathrm{X}$ (left to right) and $\mathrm{Y}$ (bottom to top) of all respondents' answer sheets. The descriptors were then collected and analysed for redundancy. Words that had very similar meaning were grouped (e.g. 'sour' and 'acidic'). Data from projective mapping methods can be analysed by a number of different multivariate data analysis methods (Varela and Ares, 2012). Traditionally, one-block data analysis methods, such as generalised procrustes analysis (Risvik et al., 1994), or multiple factor analysis (Pagès, 2003) are applied. However, two-block multivariate methods, such as partial least squares regression (PLSR) (Martens and Martens, 2001; Martens and Næs, 1989), provide better diagnostic tools for evaluation of the statistical models. Hence we used PLSR in the present application. It was carried out as an analysis of variance-partial least squares regression (ANOVA-PLSR) (Martens and Martens, 2001), where the $\mathrm{X}$-matrix consists of the experimental design, and the Y-matrix consists of the collected positions and descriptors from each respondent.

The PLSR analysis generates a map of the samples based on individual maps of the respondents. The data analysis uses sample position to establish the dimensions of (dis)similarity based on sample position, down-weighting descriptors in the analysis to one one-millionth the weight of positions (Frøst et al., 2014) so that they do not impact the projective mapping, but are used solely after the analysis is generated to interpret its underlying dimensions. To further exclude from the analysis the impact of a priori assumptions of the samples' (dis)similarity as a function of the experimental design (4 distinct locations $\times 2$ developmental stages), 
the experimental factors are down-weighted (also to one one-millionth) relative to the identity matrix. For all data analysis, model validity is evaluated with full crossvalidation. Data analysis was carried out with Unscrambler version 10.3 (Camo ApS, Oslo, Norway).

\section{Results and discussion}

\section{Explained variance}

The 10 respondents generated a total of 71 different words to describe the sensory properties of the bee brood. Of these descriptors, 9 were evaluated to have the same meaning as other words, and were merged into words with the same meaning. Seventeen of the descriptors were unique, i.e. only one respondent had used the descriptor for exactly one product. The total number of generated descriptors was relatively low, likely a consequence of having asked each subject to give no more than five descriptors per sample. However, the amount of descriptors does not say much about the difference between the bee brood samples. The analysis shows that the first two factors account for $55.4 \%$ of the total variance of the individual respondents' understanding of the similarities/differences between the samples - a fair degree of explained variance for the present number of samples and panellists.
The positioning of the bee brood samples is shown in Figure 1 . There is a clear systematic difference in sensory properties according to the developmental stage of the brood. The first dimension separates pupae samples to the left side, and larvae samples to the right. The second dimension shows a clear separation of the bee brood from Amager from those from the other three locations. Furthermore, the brood from Austmarka (NO) and Frederiksberg (DK) show relatively large differences between their pupae and larvae, while the brood from the two other locations (Gyrstinge and Amager) show smaller differences between developmental stages.

Figure 2 shows the characteristics that distinguish the samples. Each subject's individual positioning of samples is what drives the formation of the projective mapping; the descriptors they use then help to characterise the dimensions of variance. The pupae are generally characterised by having a more savoury and umami flavour and a more chewy texture. In contrast, the larvae are sweet and fruity, and have a more fragile skin, giving a softer, homogeneous texture. The larvae and pupae from Amager are characterised by a particular intensity, manifesting as notes of walnuts and herbs (grass, herbaceous, celery and green peas). This profile is contrasted by the samples from

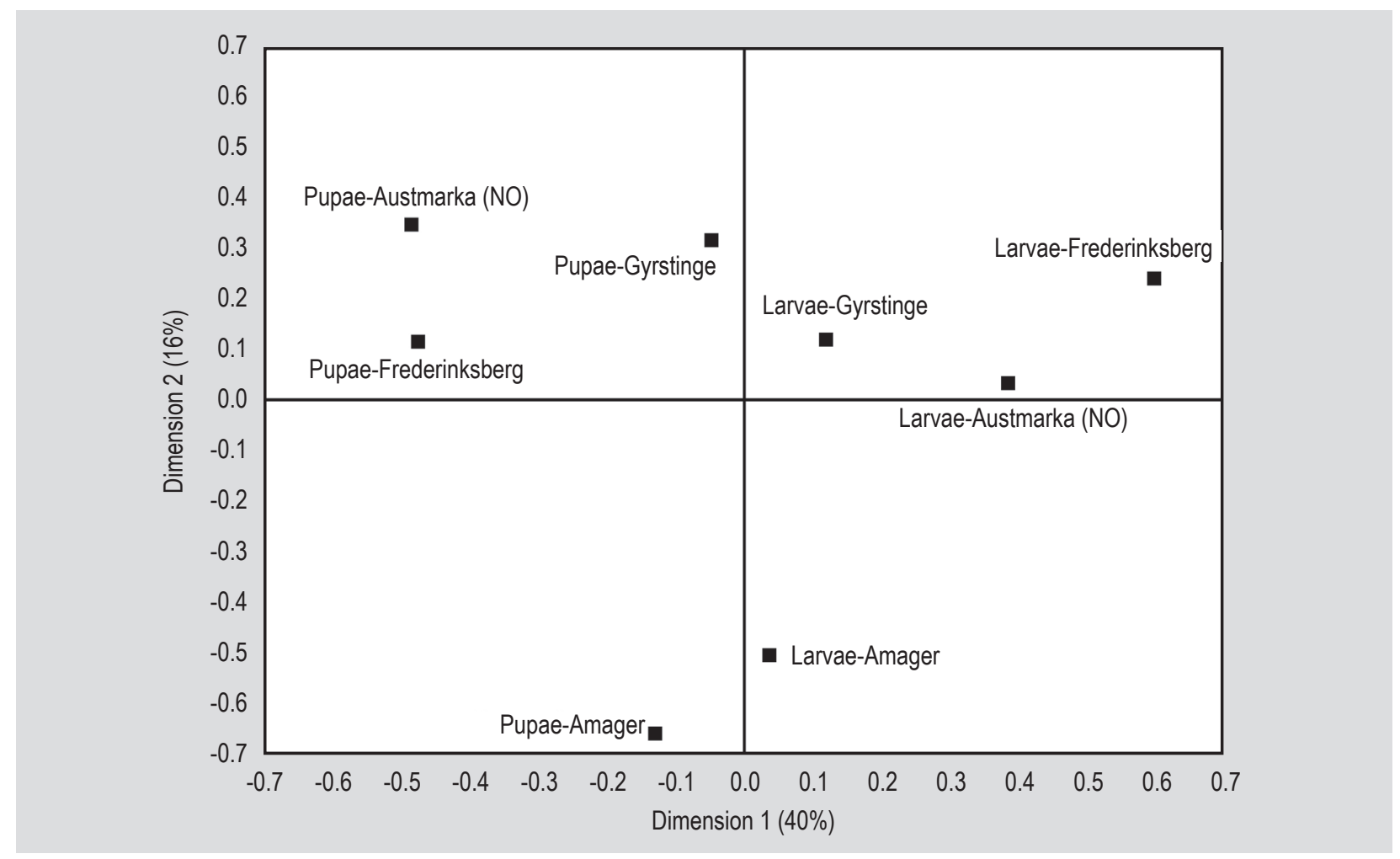

Figure 1. Correlation loading plot from partial least squares regression for factors 1 and 2: map of 8 bee brood samples (X-variables). 


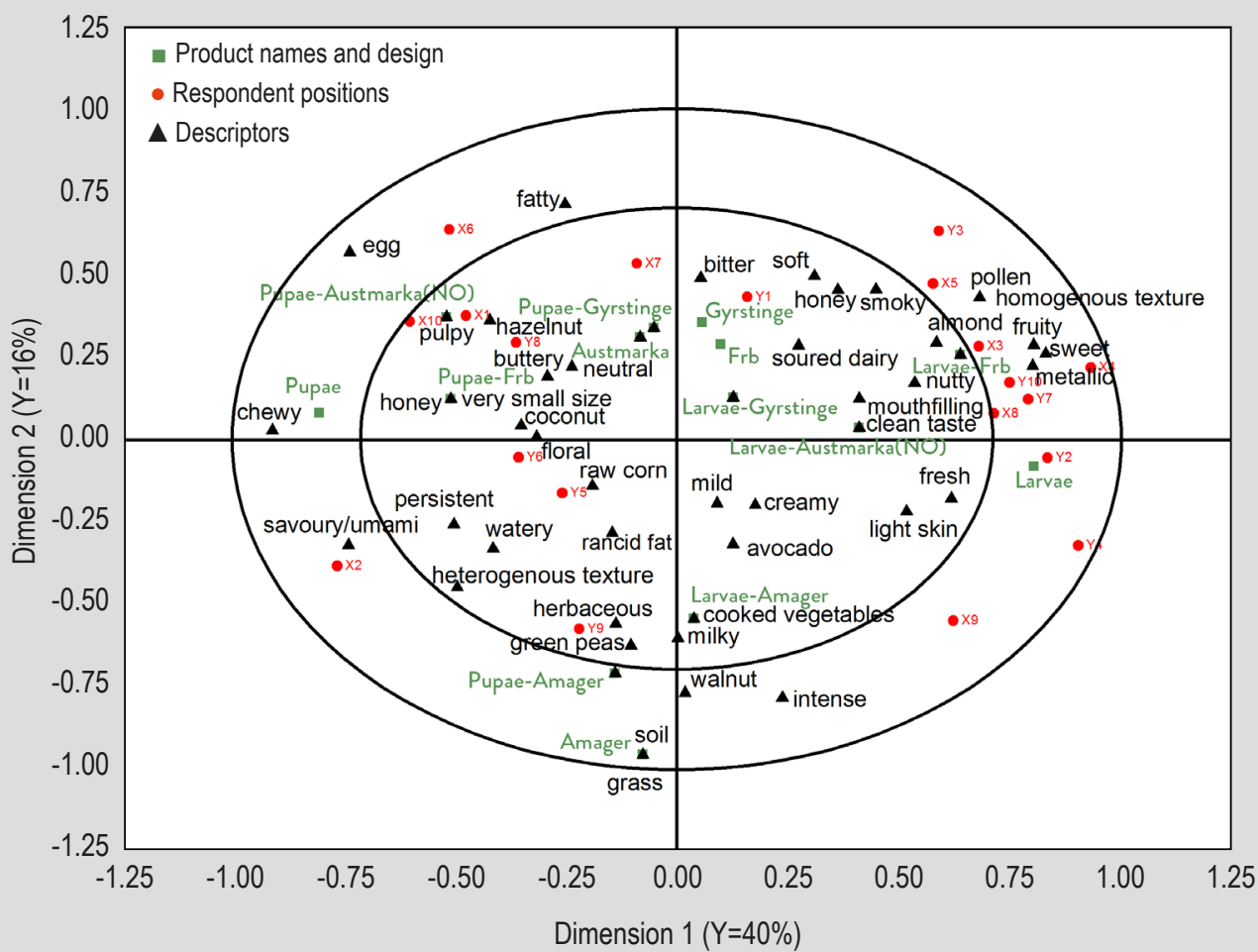

Figure 2. Correlation loading plot from partial least squares regression for factors 1 and 2: map of respondents' positioning ( $X$ and Y) followed by respondent number 1-10 (red), and descriptors (black) used by respondents for sensory properties of the bee brood.

Table 2. Common descriptors used by panellists.

\begin{tabular}{|c|c|}
\hline Descriptor & $\begin{array}{l}\text { Sample } \\
\text { (number of subjects using the descriptor) }\end{array}$ \\
\hline ‘milky’ & pupae from Amager (3) \\
\hline 'sweet' & larvae from Austmarka (5) and Frederiksberg (5) \\
\hline 'creamy' & larvae from Gyrstinge (3) \\
\hline 'mild' & larvae from Austmarka (3) \\
\hline 'nutty' & larvae from Frederiksberg (3) \\
\hline 'savoury'/'umami' & $\begin{array}{l}\text { pupae from Gyrstinge (3), Frederiksberg (4), } \\
\text { Amager (3), and Austmarka (2) }\end{array}$ \\
\hline 'chewy' & $\begin{array}{l}\text { pupae from Gyrstinge (3), Frederiksberg (4), } \\
\text { Amager (4), and Austmarka (5) }\end{array}$ \\
\hline 'floral' & pupae from Austmarka (3) \\
\hline
\end{tabular}

the other three locations, which were characterised as more subtle, fatty, and/or bitter.

Other notable descriptions across multiple subjects can be found in Table 2. These were the descriptors used by at least three panellists to characterise the same sample, and thus represent the areas of most consensus among the panellists regarding individual samples.
The included words were used for one sample by three or more subjects; this data is only to indicate recurring themes and does not claim statistical significance.

\section{Salience of developmental stage}

Why might the larvae and pupae have such distinctly different tastes? Is it more related to general physiological changes (and subsequent impact on texture), or to what extent might it also be related to differences in their food substrates? One initial hypothesis was that within a location, the local forage fed to the brood might change over time during its development, leading to different tastes between the drone larvae and drone pupae at a given moment in the season. Yet a review of bee developmental biology suggests this hypothesis may be unlikely (Winston, 1991). Of the drone brood used in this analysis, the youngest would have been the final larval instar, also called the pre-pupae, the stage when the cell is capped about 10 days after the egg is laid, and the oldest would have been at most 4 days older, an early pupa instar before their eyes turn purple - not a very long window for the local forage to change significantly according to the season.

Though there is not so much research on the particularities of drone brood diet, it is known that drone brood are typically fed substantial amounts of pollen after 4 days, compared with workers which are fed virtually none 
(Haydak, 1957). This fact, regardless of differences in pollen composition, could also account for taste differences between larvae and pupae from a given location. Thus the outstanding question is: why are Amager's larvae and pupae so similar to each other, when the larvae and pupae of the other locations are significantly different from each other - a difference which cannot be accounted for by bee developmental physiology alone? This question may be the subject of further study, and may investigate multiple factors such as differences in beekeeping practice as well as the surrounding environment.

\section{Possible genetic contributions to taste differences}

The subspecies in this experiment were either A. m. carnica (Norwegian colony) or A. mellifera $\times$ buckfast (Danish colonies). The latter is a hybrid made by crossing a number of different subspecies, where $A$. m. ligustica contributes to the majority of its genetics. A. m. carnica and A. m. ligustica are very closely related (Wallberg et al., 2014) and we doubt that the genetics of the colonies per se should have a large influence on the taste of the drone brood, though we do not have experimental data to support this hypothesis.

Another possible mechanism for genetic influence on taste could be that different subspecies have different dietary preferences. Honeybees forage on a variety of plants to obtain pollen and nectar. Colonies in the same apiary (related colonies) have been documented to select different pollen sources across time (R. Brodschneider et al., unpublished data). These differences can be related to the honeybee foraging strategies, where sending out scouts in search of pollen and nectar sources can result in different utilisation of plant species within flight range. Colonies might also need to collect kinds of pollen that complement previous pollen diets, for example with respect to different amino acid content from different kinds of forage over a season (Hendriksma and Shafir, 2016).

A number of different subspecies are used in European beekeeping, but we are not aware of studies that have compared forage selection across different subspecies. Some subspecies such as Caucasian bees have longer tongues and are better adapted to collect nectar from flowers such as red clover (Ruttner, 1975), but in general the potential effect of genetic factors on the taste of drone brood seem to be less important than the environmental factors in the current study.

\section{Limitations of the chosen sensory methodology}

The sensory methods employed here, as with any methods, have certain limitations. The projective mapping method is a fast sensory method that provides robust but possibly less precise descriptions than conventional sensory profiling (Dominique et al., 2012). Furthermore, the subsequent data analysis extracts the patterns that emerge from the aggregate of subjects' responses (Martens and Martens, 2001, Chapter 3), and thus excludes the idiosyncratic taste patterns of individual samples for individual subjects. In addition, the visual differences between the larvae and pupae could have influenced the sensory analysis, and it could be fruitful to repeat the experiment with a blind panel.

\section{Conclusions and future directions}

This study gestures towards the multifaceted - and in many parts of the world, neglected - culinary potential of bee brood, and encourages its further exploration. The fastsensory method demonstrated clear differences between the samples - mainly between developmental stages, but also to some degree between brood from different locations.

This is a preliminary study, but it shows directions for further research: for example, gathering more data about local forage, pollen sources, temperature, and weather conditions around the colonies would enable use of more precise categories than 'urban/rural' and 'monocultural/ polycultural' to characterise the hives' surroundings, and would thus make it possible to investigate more robust correlations between these data and similarities and differences in taste.

This study, in demonstrating a noticeable sensory difference between larvae and pupae, supports field observations that they are treated differently in certain cuisines. This differentiation is a key to fully develop bee brood's culinary potential as a normal, culturally appropriate food, and even, in certain contexts, as a delicacy.

\section{Acknowledgements}

This experiment was carried out as part of the project 'Discerning taste: deliciousness as an argument for entomophagy', grant number 32726 funded by the Velux Foundation.

We would like to thank the four beekeepers who supplied us with drone brood: Cirkeline Brandt from Gyrstinge, Denmark; Oliver Maxwell and the team at Bybi on Amager, Copenhagen, Denmark; Viggo Jessen and the local beekeeper association for Copenhagen municipality located at the University of Copenhagen, Frederiksberg, Denmark; and Trude Sommerstad in Austmarka, Norway. We would also like to thank Flemming Vejsnæs at Danmarks Biavlerforening and Eli Åsen at Norbi for facilitating the harvesting and transport of the brood from Norway to Copenhagen. 


\section{References}

Barthouil, G., 2013. Spis flere af biernes produkter. Tidsskrift for Biavl 147: 228-231.

Calis, J.N.M., 2001. Parasite-host interactions between the Varroa mite and the honey bee: a contribution to sustainable Varroa control. $\mathrm{PhD}$ thesis, Wageningen UR, Wageningen, the Netherlands.

Charriere, J.D., Imdorf, A., Bachofen, B. and Tschan, A., 2003. The removal of capped drone brood: an effective means of reducing the infestation of Varroa in honey bee colonies. Bee World 84: 117-124.

Delholm, C., 2012. Descriptive sensory evaluations, comparison and applicability of novel rapid methodologies. $\mathrm{PhD}$ thesis, University of Copenhagen, Copenhagen, Denmark, 154 pp.

Dietemann, V., Pflugfelder, J., Anderson, D., Charrière, J.D., Chejanovsky, N., Dainat, B., De Miranda, J., Delaplane, K., Dillier, F.X., Fuch, S., Gallmann, P., Gauthier, L., Imdorf, A., Koeniger, N., Kralj, J., Meikle, W., Pettis, J., Rosenkranz, P., Sammataro, D., Smith, D., Yañez, O. and Neumann, P., 2012. Varroa destructor: research avenues towards sustainable control. Journal of Apicultural Research 51: 125-132.

Dominique, V., Chollet, S., Lelièvre, M. and Abdi, H., 2012. Quick and dirty but still pretty good: a review of new descriptive methods in food science. International Journal of Food Science and Technology 47: 1563-1578.

Evans, J., 2012. Non-trivial pursuit - new approaches to Nordic deliciousness. Anthropology of Food 18: 895-897.

Evans, J., Flore, R., Pedersen, J.A. and Frøst, M.B., 2015. Place-based taste: geography as a starting point for deliciousness. Flavour 4(7): 6 .

Frøst, M.B., Giacalone, D. and Rasmussen, K.K., 2014. Alternative methods of sensory testing: working with chefs, culinary professionals and brew masters. In: Delarue, J., Lawlor, J.B. and Rogeaux, M. (eds.) Rapid sensory profiling techniques and related methods - applications in new product development and consumer research. Woodhead Publishing, Cambridge, UK, pp. 363-382.

Fuchs, S. and Langenbach, K., 1989. Multiple infestation of Apis mellifera brood cells and reproduction in Varroa jacobsoni Oud. Apidologie 20: 257-266.

Gade, B. and Theuerkauf, R., 2016. Biavl: bier, blomster og honning. Lindhardt og Ringhof, Copenhagen, Denmark.

Haydak, M.H., 1957. The food of the drone larvae. Annals of the Entomological Society of America 50(1): 73-75.

Halloran, A., Münke, C., Vantomme, P., Reade, B. and Evans, J., 2015. Broadening insect gastronomy. The routledge handbook of sustainable food and gastronomy. Taylor and Francis, Abingdon, UK, pp. 199-205.

Hendriksma, H.P. and Shafir, S., 2016. Honey bee foragers balance colony nutritional deficiencies. Behavioral Ecology and Sociobiology 70: 509-517.

Jonas-Levi, A., Benjamin, O., Martinez, J.J.I., 2015. Does a parasite infestation change the nutritional value of an insect? Varroa mites on honey bees as a model. Journal of Insects for Food and Feed 1: $141-147$
Lawless, H.T. and Heymann, H., 2010. Sensory evaluation of foods principles and practices. Springer, New York, NY, USA.

Lensvelt, E. and Steenbekkers, L., 2014. Exploring consumer acceptance of entomophagy: a survey and experiment in Australia and the Netherlands. Ecology of Food and Nutrition 53: 543-561.

Martens, H. and Martens, M., 2001. Multivariate analysis of quality an introduction. Wiley and Sons Ltd., Chichester, UK.

Martens, H. and Næs, T., 1989. Multivariate calibration. Wiley and Sons Ltd., Chichester, UK.

Müller, A., Evans, J., Payne, C. and Roberts, R., 2016. Entomophagy and power. Journal of Insects for Food and Feed 2: 121-136.

Pagès, J., 2003. Direct collection of sensory distances: application to the evaluation of ten white wines of the loire valley. Sciences des Aliments 23(5-6): 679-688.

Perrin, L. and Pages, J., 2009. Construction of a product space from the ultra-flash profiling method: application to 10 red wines from the loire valley. Journal of Sensory Studies 24: 372-395.

Risvik, E., Mcewan, J.A., Colwill, J.S., Rogers, R. and Lyon, D.H., 1994. Projective mapping: a tool for sensory analysis and consumer research. Food Quality and Preference 5: 263-269.

Rosenkranz, P., Aumeier, P. and Ziegelmann, B., 2010. Biology and control of Varroa destructor. Journal of Invertebrate Pathology 103: S96-S119.

Rumpold, B.A. and Schlüter, O.K., 2013. Nutritional composition and safety aspects of edible insects. Molecular Nutrition and Food Research 57: 802-823.

Ruttner, F., 1975. Races of bees. In: Hamilton, I.L. (ed.) The hive and the honey bee. Dadant and Sons, Hamilton, IL, USA, pp. 19-38.

Schulz, A.E., 1984. Reproduction and population-dynamics of the parasitic mite Varroa jacobsoni Oud - and its dependence on the brood cycle of its host, Apis mellifera. Apidologie 15: 401-419.

Tan, H.S.G., Fischer, A., Tinchan, P., Stieger, M., Steenbekkers, L. and Van Trijp, H., 2015. Insects as food: exploring cultural exposure and individual experience as determinants of acceptance. Food Quality and Preference 42: 78-89.

Van Huis, A., Van Itterbeeck, J., Klunder, H., Mertens, E., Halloran, A., Muir, G. and Vantomme, P., 2013. Edible insects: future prospects for food and feed security. Food and Agriculture Organization of the United Nations (FAO), Rome, Italy, FAO Forestry Paper no. 171, 201 pp. Available at: http://www.fao.org/docrep/018/i3253e/i3253e.pdf. Varela, P. and Ares, G., 2012. Sensory profiling, the blurred line between sensory and consumer science. A review of novel methods for product characterization. Food Research International 48: 893-908.

Vejsnæs, F., Jørgensen, A.S. and Theuerkauf, R.T., 2005. Varroa and its control. Tidsskrift for Biavl, Særnummer 8.

Wallberg, A., Han, F., Wellhagen, G., Dahle, B., Kawata, M., Haddad, N., Simões, Z.L.P., Allsopp, M.H., Kandemir, I., De la Rúa, P., Pirk, C.W. and Webster, M.T., 2014. A worldwide survey of genome sequence variation provides insight into the evolutionary history of the honeybee Apis mellifera. Nature Genetics 46: 1081-1088.

Winston, M.L., 1991. The biology of the honey bee. Harvard University Press, Cambridge, MA, USA. 
